Chimia 46 (1992) 69-77

(c) Schweiz. Chemiker-Verband; ISSN 0009-4293

\title{
Liposomes and Immuno- liposomes as Carriers for Cytostatic Drugs, Magnetic Resonance Contrast Agents, and Fluorescent Chelates
}

\author{
Reto A. Schwendener*
}

\begin{abstract}
Biological and medical applications of liposomes as carriers for cytostatic drugs, magnetic-resonance contrast agents, and fluorescent markers are presented. The cytostatic effects of liposomal preparations of lipophilic derivatives of cytosine arabinoside (ara-C), namely $N^{4}$-oleyl-ara-C (NOAC) and $N^{4}$-alkyl-ara-C are demonstrated in the mouse L1210 tumor model. Liposomal drugs were more effective by factors of 2-10 as compared to ara-C administered in aqueous preparations. Synergistic effects of the combination of ara-C and mitoxantrone could be shown, again with significantly increased effects, when the drugs were administered in liposomes. A practical detergent-dialysis method for the preparation of large volumes of sterile liposomes for clinical use is presented. Clinical phase I/II studies of liposomal NOAC and mitoxantrone are currently in progress. Methods of preparation of immunoliposomes, i.e. the coupling of antibodies or antibody subunits to liposome membranes, are discussed and results of specific immunoliposome - cell binding are presented. Possibilities of increasing the blood circulation times of liposomes by incorporation of lipophilic derivatives of poly(ethylene glycol) into the liposome membranes are shown. The successful application of liposomes as carriers of paramagnetic metal complexes as contrast agents in magnetic-resonance imaging for liver and spleen is documented. Finally, the concept of liposomes as carriers for fluorescent Europium chelates as markers for time-resolved flow cytometric applications are presented.
\end{abstract}

\section{General Properties of Liposomes}

Liposomes are spherical vesicles prepared from natural or synthetic phospholipids and cholesterol. Their mean diameters range from 0.02 to $2 \mu \mathrm{m}$ depending on the method of preparation, lipid composition, and concentration and the properties of added molecules. Liposomes are composed of either one (unilamellar liposomes) or several (oligo- or multilamellar liposomes) lipid bilayers surrounding internal aqueous volumes. According to their mean size, the liposomes are classified into either 'small unilamellar vesicles', (SUV, 20-200 nm) and 'large unilamellar vesi-

\footnotetext{
*Correspondence: Dr. R.A. Schwendener Department of Internal Medicine Medical Oncology University Hospital CH-8091 Zürich
}

cles' (LUV, >200 nm), whereas the 'multilamellar vesicles' (MLV) are of heterogenous size distribution $(0.1 \rightarrow 2 \mu \mathrm{m})$ [14]. For most of the biological applications, homogeneous SUV's with average diameters ranging from 20 to $250 \mathrm{~nm}$ are better suited than heterogenous MLV preparations. Depending on the particular physico-chemical properties, hydrophilic molecules (drugs, contrast agents, fluorescent probes, proteins, nucleotides, etc.) can be entrapped within the internal aqueous space of a liposome, whereas lipophilic molecules are incorporated into the phospholipid membrane. Additionally, antibodies, proteins, and haptens can be covalently attached to the outer surface of the liposomes either to enable specific binding to defined targets or to serve as antigens for immunization. Liposomes allow the parenteral administration of insoluble or poorly soluble drugs. Toxic side effects on organs and cells can be reduced or elimi-

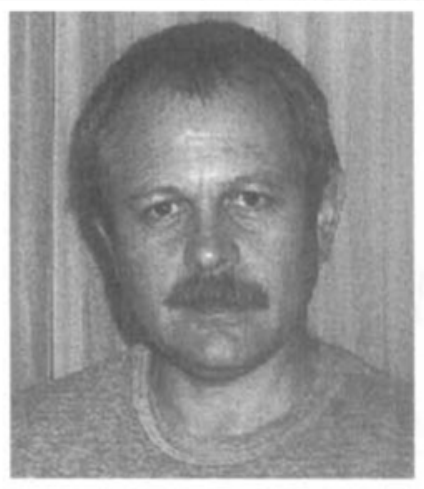

Reto Albert Schwendener: Born May 19, 1948 in Chur, Switzerland. 1969-75 Study of Pharmacy at the ETH in Zürich; Dipl. Pharmacist ETH. 1976-79 Doctorate at the ETH-Zürich with Prof. H.G. Weder. Thesis: 'Liposomes as potential drug carriers: binding and incorporation studies with the neuroleptic drug chlorpromazine'. 1977-80 Assistant at the Pharmaceutical Institute ETH, Physical Pharmacy and Biopharmacy. 1981 Postdoctoral Fellow at the University of California, Davis, USA; Prof. D.W. Deamer, Institute of Zoology. 1982 Postdoctoral Fellow at the Argonne National Laboratory, Argonne (Chicago), IL, USA; Prof. Y.E. Rahman, Medical and Biological Division. 1983-84 Oberassistent at the Pharmaceutical Institute ETH, Physical Pharmacy and Biopharmacy. 1985-88 Oberassistent at the Institute of Pathology, Department of Experimental Pathology, Prof. R. Zinkerna$\mathrm{gel}$ and Prof. H. Hengartner, University Hospital, Zürich. 1987 Visiting scientist at the University of Minnesota, Minneapolis, MN, USA; Prof. Y.E. Rahmen, Dept. of Pharmaceutics. 1989-90 Oberassistent at the Department of Radiology, Division of Nuclear Medicine; Prof. W.A. Fuchs and Prof. G.K. von Schulthess, University Hospital, Zürich. 1991 Oberassistent at the Department of Internal Medicine; Prof. F. Follath, Division of Medical Oncology; Prof. Ch. Sauter, University Hospital, Zürich. Submission of the Habilitation thesis: 'Liposomen als Träger von Zytostatika und Neuroleptika: Ein mögliches Verfahren zur organ- oder zellspezifischen Terapie'. At the Faculty of Medicine, University of Zürich

nated by liposomal drug delivery. Fast drug elimination and metabolism can be retarded with liposomal formulations.

The incorporation of molecules into the lipid membrane as shown schematically in Fig. 1 offers several advantages over the encapsulation of small hydrophilic molecules into the entrapped aqueous volume of a liposome. Firstly, the stability of incorporation is higher, because diffusion and leakage of lipophilic molecules into the aqueous medium surrounding the liposomes is negligible. Secondly, the rate of incorporation during liposome formation is virtually quantitative and procedures to separate unincorporated molecules from the liposomes are not necessary ( $c f$. Table 1), and thirdly, the drug-carrying lipo- 


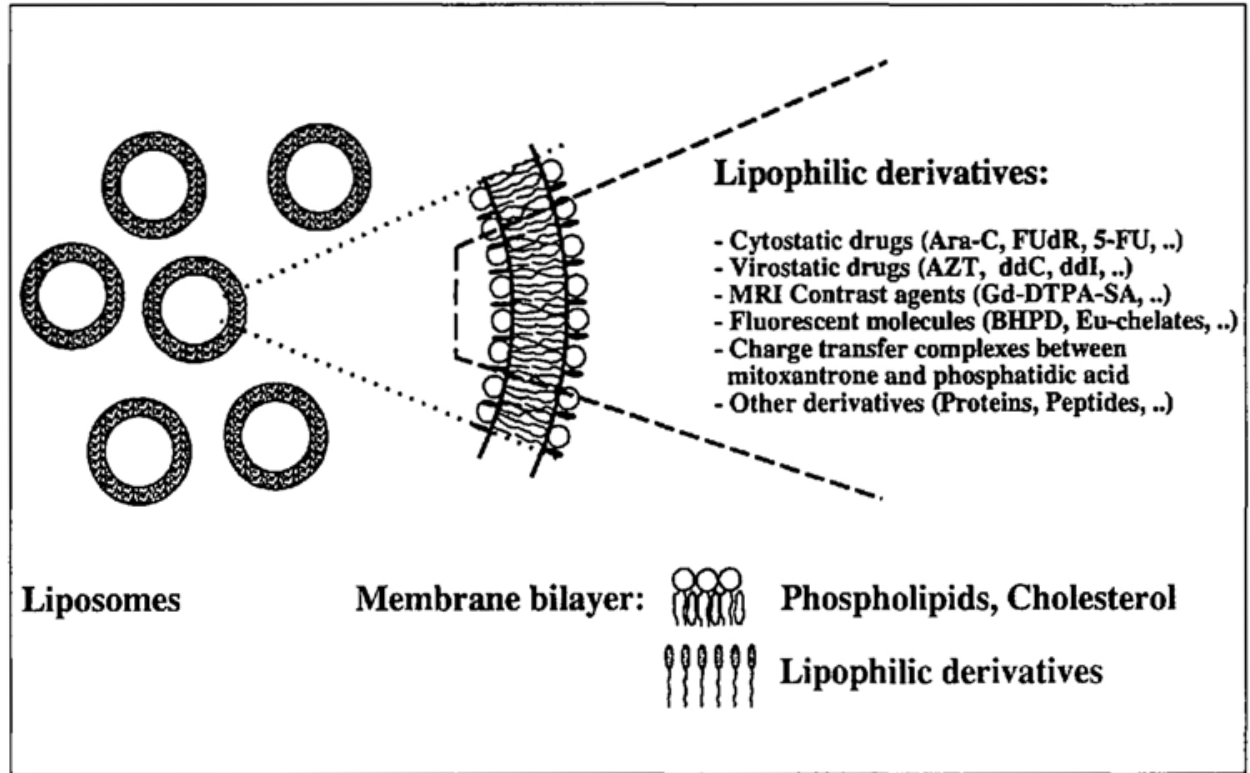

Fig. 1. Schematic representation of the incorporation of lipophilic molecules into a liposome bilayer membrane. Hydrophilic molecules are modified with long-chain fatty acids, alkyl chains, or they are attached to phospholipids (e.g. phosphatidyl ethanolamine). Strong complex formation between lipophilic acids (phosphatidic acid) and basic molecules (e.g. mitoxantrone) yield stable drugcontaining liposomes.

somes can be prepared by the detergentdialysis method which offers several advantages mainly for the preparation of large quantities of sterile liposomes (see 2.3). A disadvantage encountered in the use of lipophilic molecules is that chemical modifications of the originally hydrophilic drug are often necessary, e.g. the modification of cytosine arabinoside (araC) into $N^{4}$-oleyl-or $N^{4}$-alkyl-cytosine arabinoside (NOAC, $N^{4}$-hexadecyl-ara-C).

Many methods of liposome preparation and characterization are in use. Together with many applications in biochemistry and biology, they have been described and discussed in several reviews [1-4].

Fate and behaviour of liposomes in vivo are very complex, and mainly depending on liposome size and population homogeneity, lipid composition and site of administration [5]. Two major events can take place when liposomes are introduced into a body compartment: $a$ ) liposomal contents may be released under the influence of the biological environment (e.g. interactions with serum proteins) and/ or $b$ ) liposomes can be transported to certain compartments where liposomes or some or all of the liposomal drug may be taken up by cells. The kinetic rates of $a$ determine the extent of drug uptake in $b$. Thus, factors that control the physical stability of the liposomes in vivo are of paramount importance. Due to their particulate properties, liposomes and most of other drug carriers are taken up by the cells of the mononuclear phagocyte system (MPS), i.e. mainly by liver, spleen, bone marrow, and lymph nodes.

This property may either be advantageous, when the molecule of interest is to be targeted to the MPS, or disadvantageous, when the sites of delivery are elsewhere in the body. Thus, the development of liposome preparations that reduce uptake of the MPS and prolong blood circulation of liposomal drugs are a major task in liposome research.

On the cellular level, liposomes interact with cell membranes by adsorption, endocytose, membrane fusion, and lipid exchange, or by a combination of these mechanisms [9]. It is conceivable that mechanisms of cancer-drug resistance may be circumvented by liposomal drug delivery in a way that cellular drug uptake and intracellular transport mechanisms can be altered [10].

The main purpose of this publication is to present the author's recent work in the field of liposome applications in biology and medicine. For more profound informations on liposome preparation methods, physicochemical properties, in vivo by Detergent Dialysis ${ }^{\mathrm{a}}$ ) $100 \%$. behaviour, and other applications of liposomes, the reader is referred to reviews and publications where these aspects are dealt with [1-5][9-15].

\section{Application of Liposomes in Biology and Medicine}

\subsection{Development of Liposomes with Prolonged Blood Circulation}

With synthetic phospholipids of high liquid-crystal to solid-phase transition temperature, of poly(ethylene glycol)-linked lipids or of glycolipids [6][7], liposomes can be made more resistant to degradation in circulation and to fast absorption in the organs of the MPS.

We have used the two lipophilic poly(ethylene glycol) derivatives cholesteryl-poly(ethylene glycol) 900 sebacat (chol-PEG(900)) and poly(ethylene glycol) (5000)-phosphatidylethanolamide (PEG(5000)-PE) [6][8] for the preparation of hydrophilic liposomes. As shown in Fig. 2, the blood kinetics of such liposomes can be influenced by the addition of PEG derivatives. Chol-PEG(900) has little effect upon prolongation of the circulation of the liposomes, whereas with the derivative of higher molecular weight higher and longer lasting levels of the $\mathrm{I}^{\mathbf{1 2 5}}$. labelled ( $c f$. Methods) liposomes were found in the blood. The degree of ethylene glycol polymerization influences the interactions of the liposomes with blood components. Short PEG chains (e.g. cholPEG(900)) provide no increased blood stability of the liposomes. The elimination half-time $\left(t_{1 / 2}\right)$ from the circulation of liposomes without chol-PEG(900) was $1.2 \mathrm{~h}$ and that of liposomes containing $40 \mathrm{~mol}-$ $\%$ of chol-PEG(900) $1.1 \mathrm{~h}$. In contrast, a blood elimination half-time of $3.4 \mathrm{~h}$ was determined with the more hydrophilic PEPEG(5000) derivative.

The increased stability of such liposomes in circulation can for instance be

Table 1. Incorporation Characteristics of Cytostatic Drugs and Derivatives in Liposomes Prepared

\begin{tabular}{|c|c|c|c|c|}
\hline \multirow[t]{2}{*}{ Drug } & \multicolumn{2}{|c|}{ Incorporation } & \multicolumn{2}{|c|}{ Liposome diameter $[\mathrm{nm}]$ after } \\
\hline & $\left.\mu \mathrm{g} / \mathrm{ml}^{\mathrm{b}}\right)$ & {$[\%]$} & $\left(d^{c}\right)$ & $300 \mathrm{~d}$ \\
\hline ara-C & 19 & 3.8 & 110 & 102 \\
\hline $\mathrm{N}^{4}$-oleyl-ara-C & 581 & 88 & 108 & 109 \\
\hline $\mathrm{N}^{4}$-hexadecyl-ara-C & 555 & 91 & 117 & 124 \\
\hline
\end{tabular}

a) Results taken in part from [29]. Liposome preparation by capillary detergent dialysis [34].

b) Incorporation efficiency of the drugs was determined by UV spectroscopy or with radiolabeled are- $\mathrm{C}$ derivatives. The initial drug concentration in the micelles was taken as

c) Hydrodynamic liposome diameters were measured by laser light scattering [62]. 
exploited for the development of liposome preparations containing cytostatic drugs or contrast agents for the vascular system (see 4). Blume and Cevc [8] prepared liposomes with the saturated phospholipid distearoyl phosphatidylcholine (DSPC) and 10 mol-\% of the DSPEPEG (5000) derivative. The blood elimination half-time of these very stable liposomes was $8.4 \mathrm{~h}$. These results demonstrate that liposomes of variable kinetic properties can be prepared. According to their particular compositions, their in vivo behaviour can be tailored according to the desired application, i.e. long lasting blood circulation or fast absorption in the organs of the MPS.

\subsection{Liposomes as Carriers for Pharmacologically Active Compounds}

In the search of new approaches for the chemotherapy of malignant diseases the following strategies are being pursued: $a$ ) Exploration of new combinations with different dosing and therapy regimens with existing drugs [16]. b) Search for new drugs with new pharmacological properties, and $c$ ) the improvement of the effectiveness of existing drugs using methods to alter drug disposition, kinetics and doseresponse relationships with the aim to achieve a higher therapeutic index [11]. Such improvements may be accomplished by chemical modifications of the active drugs and with the development of drug delivery systems. An optimal drug delivery system must be capable to selectively localize the targets in an organism where disease resides and to release the drugs at suitable rates while producing the minimum of untoward side effects. Among a variety of possible drug delivery systems, liposomes offer several advantages: a) Flexibility in formulation of their composition and size and $b$ ) the opportunity to use drugs of known pharmacological properties.

These advantages may, however, also evoke disadvantages. Since the possibilities of liposome preparation and composition are almost infinite and each formulation involves different clinical pharmacology trials, it is necessary to perform time consuming preclinical toxicological and pharmacological studies.

The application of liposome preparations on humans is most advanced in the field of cancer chemotherapy. Phase I/II studies have been reported with liposomal doxorubicin [17][18] and a water-insoluble quinazolone drug [19].

Other clinical applications of liposome preparations comprise the treatment of systemic mycosal infections which are common in leukemia and AIDS. The antifungal drug amphotericin $B$ can be ad-

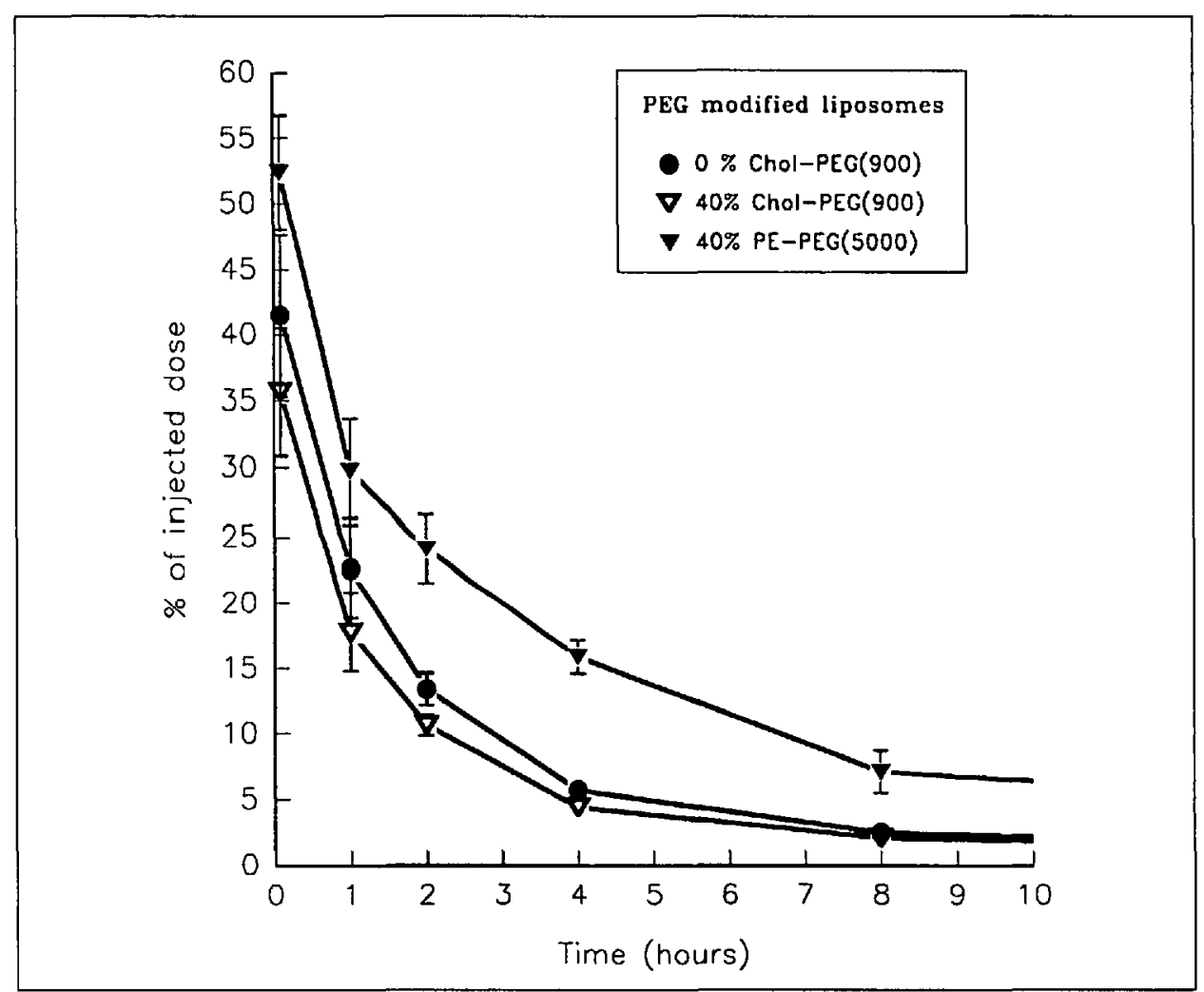

Fig. 2. Blood clearance of PEG-modified liposomes. The incorporation of lipophilic PEG derivatives into the liposome membranes increases their blood circulation time. With PE-PEG(5000)-liposomes the circulation half-time is increased to $3.4 \mathrm{~h} v s .1 .1-1.2 \mathrm{~h}$ of unmodified liposomes or liposomes containing the less effective chol-PEG $(900)$ derivative.

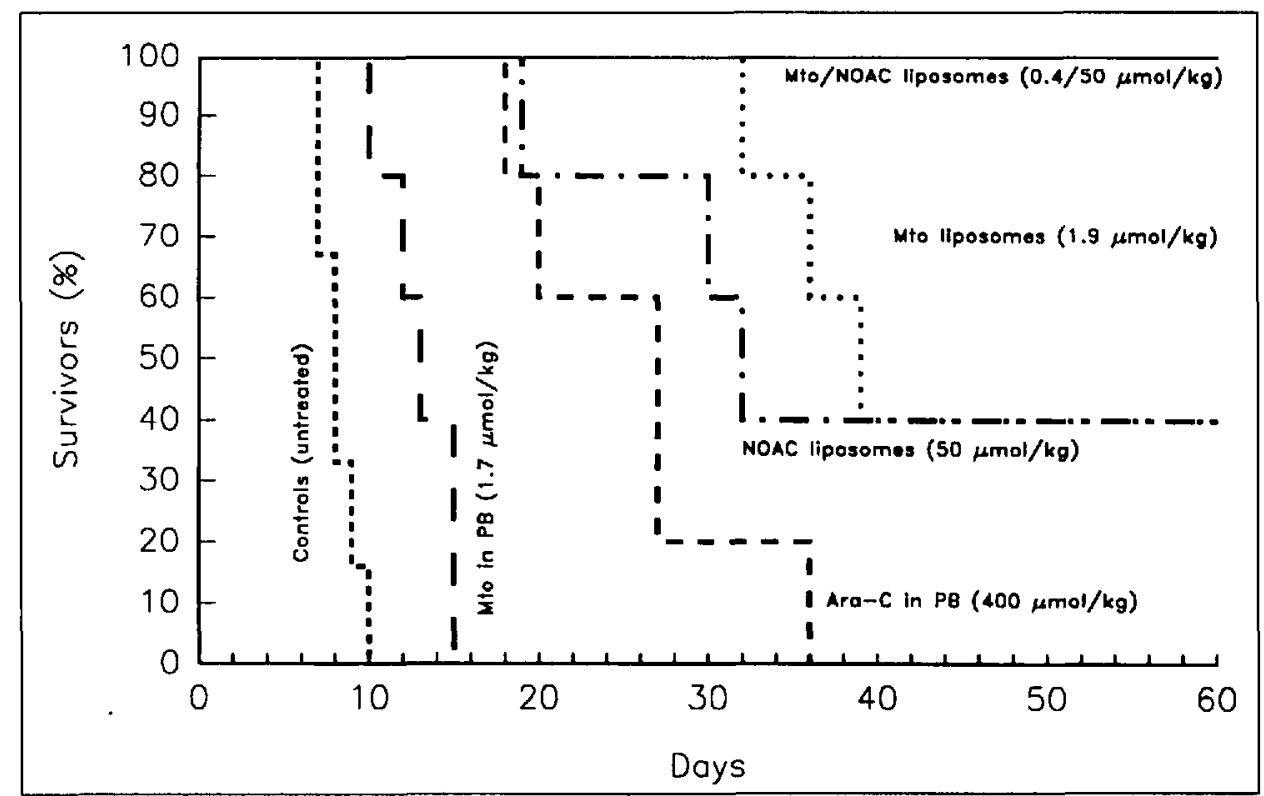

Fig. 3. Synergistic effect of cytostatic drug combinations. Survival curves of the treatment of L1210 leukemia in mice with single drugs and drug combinations either as free drugs or as liposomal drug applications.

ministered at higher doses and with improved effects in a liposomal preparation [20].

The lipophilic muramyltripeptidephosphatidyl ethanolamide (MTP-PE), a macrophage-activating agent, is presently being studied as liposome preparation in patients with advanced cancer [21].

Liposomes loaded with In ${ }^{11}$ complexes or other radiolabels can successfully be used for the diagnostic imaging of human primary and metastatic cancer [22].
Synergistic effects between cytostatic drugs have been demonstrated in vivo with different conventional and liposomal drug combinations [23-27]. We investigated the cytotoxic effect of the combination therapy of ara-C and mitoxantrone in the L1210 mouse leukemia model. In Fig. 3 the synergism of the lipophilic ara-C derivative $\mathrm{N}^{4}$-oleyl-cytosine arabinoside (NOAC) and mitoxantrone, both incorporated into liposomes is shown. Female $\mathrm{BDFI}$ mice inoculated intraperitoneally 
with L1210 leukemia cells were treated by the intravenous route either with the single drugs dissolved in buffer (ara-C, mitoxantrone), or with the single-drugs in liposomes (NOAC, mitoxantrone-phosphatidic acid complex, [28]), and finally with the combination of both liposomal drugs. The liposomal drugs were in all cases more effective, compared to the single-drug therapy and especially as combination of NOAC and mitoxantrone where all treated animals survived 60 days [29][30].
In another experiment summarized in Table 2, we could demonstrate the superior cytostatic action of liposomal lipophilic derivatives of ara- $\mathrm{C}$ in comparison to the free drug. Total doses of the liposomal ara- $C$ derivatives which were $2-4$ times below those of free ara-C were more effective against the L1210 leukemia. The length of the alkyl chain has a marked influence on the cytostatic action of the derivative. Chain lengths of less than $14 \mathrm{C}$-atoms showed no effect. This effect of side-chain

Table 2. Antitumor Effect of $\mathrm{N}^{4}$-Acyl-and $\mathrm{N}^{4}$-Alkyl Derivatives of ara-C in Liposomal Preparations: L1210 Murine Leukemia Model ${ }^{\text {a) }}$

$\begin{array}{llll}\text { Drug } & \text { Total dose } & \left.\mathrm{T} / \mathrm{C}^{\mathrm{b}}\right) & \text { Survivors }^{\mathrm{c}} \text { ) } \\ \text { preparation } & \mu \mathrm{mol} / \mathrm{kg} & {[\%]} & 60 \mathrm{~d}\end{array}$

\section{Liposomes:}

$\begin{array}{lrrr}N^{4} \text {-oleyl-ara-C } & 200 & 245 & 1 / 5 \\ & 400 & 333 & 2 / 5 \\ N^{4} \text {-dodecyl-ara-C } & 400 & 97 & 0 / 6 \\ N^{4} \text {-hexadecyl-ara-C } & 400 & 500 & 5 / 6 \\ N^{4} \text {-octadecyl-ara-C } & 400 & 714 & 6 / 6\end{array}$

Aqueous solutions: ara-C in $\mathrm{PB}$

1600

800
$0 / 6$

$0 / 5$

Controls: untreated
100 $0 / 6$

a) Tumor cell inoculation on day $0\left(10^{5} \mathrm{~L} 1210\right.$ cells $)$ intraperitonally (i.p.), treatment i.p. on days 2 and 6.

b) Increase of lifespan of treated (T) animals compared to untreated controls (C), expressed in \%.

c) Surviving animals after $60 \mathrm{~d}$ were considered as cured.

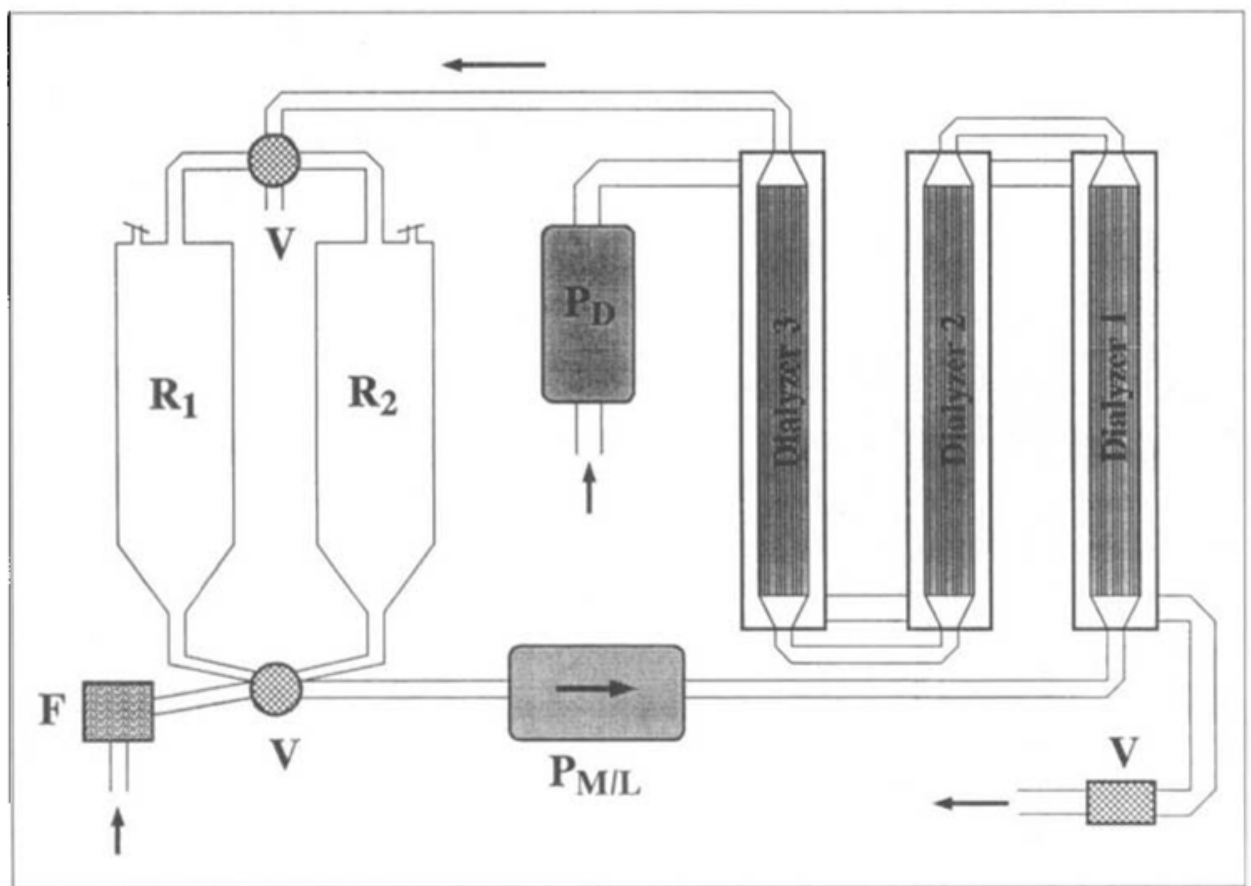

Fig. 4. Schematic drawing of the capillary dialysis instrument for liposome preparation. $\mathrm{F}$, in-line filter; $R_{1}, R_{2}$, micelle/liposome reservoirs; $V$, valves; $P_{M / L}$, micelle/liposome pump; $P_{D}$, dialysis buffer pump; dialyzer 1-3, capillary dialysis cartridges. Adapted from [34][35].

length was shown before with $N^{4}$-acyl derivatives of ara-C [31].

At the University Hospital in Zürich, we are presently conducting phase I/II studies with liposomal mitoxantrone [28][32][33] for the treatment of advanced breast cancer and indolent non-Hodgkin lymphomas. In another study, patients suffering from refractive, acute myeloid leukemia (AML) are treated with a combination of liposomal NOAC and mitoxantrone liposomes.

\subsection{Preparation of Liposomes for Clinical Applications}

The use of liposome preparations for clinical trials requires that large volumes of stable and sterile liposomes, are made available. For the preparation of the NOAC- and mitoxantrone-liposomes we have developed a convenient method of preparation which is based on the removal of detergent from mixed lipid/drug/detergent micelles by fast dialysis through capillary dialyzers [34][35]. The setup of the dialysis instrument is shown in Fig. 4. The sterile micelle solution is pumped through an in-line filter $(\mathrm{F})$ into the system. Driven by pump $\mathrm{P}_{\mathrm{M} / \mathrm{L}}$ the micelles/liposomes (M/ L) circulate in a closed circuit from the reservoirs $\left(R_{1}, R_{2}\right)$ to the serially connected capillary dialyzers (dialyzers $1-3$ ). In a counter current flow, the dialysis buffer is drawn with pump $P_{D}$ alongside the capillaries, whereby the detergent is effectively removed from the micelle solution. During dialysis, the micelles are transformed into homogeneous bilayer liposomes. The extensive dialysis guarantees the quantitative detergent removal. Depending on the lipid concentration and duration of dialysis, the amount of residual detergent can be reduced to less than $0.2 \%$ of the initial amount [34]. An example of liposome preparation for clinical application is given in the experimental section.

\section{Immunoliposomes}

The targeting of drugs, toxins, peptides, and proteins to a specific site is subject of many approaches. In cancer therapy, cytotoxic antibodies, antibodytoxin conjugates, and antibody-drug conjugates are used to obtain increased tumorcell specific cytotoxicity [36-42]. However, the use of heterologous antibodies elicits an immune reaction and the production of human-anti-mouse antibodies (HAMA). Presently, the production of human monoclonal antibodies is still not easy to achieve because of the limited possibilities of immunizing humans. Furthermore, methods for the production of stable cell lines that efficiently secrete 
human monoclonal antibodies have to be developed. Because of the limited possibilities of immunizing humans, it is presently not achievable to prepare human monoclonal antibodies. To circumvent these problems, chimeric human-mouse antibodies are being produced with molecular-biological methods [43]. Attempts are made to reduce the antibody molecules to the size of the so-called 'minimal reactive unit'(mru) which is the smallest possible peptide that recognizes and binds to specific cellular antigens [44]. Such mru's may have significant advantages over the original antibody molecules whereby preparation methods of such units and their linkage to toxins, cytostatic drugs, radionuclides, and macromolecular carriers such as liposomes have to be developed. The possibilities of fragmentation of an IgG antibody molecule into smaller subunits, namely $\mathrm{F}(\mathrm{ab})_{2}{ }^{-}, \mathrm{Fab}$-, and Fv-fragments, single chain $V_{H}$ and minimal reactive units, are schematically shown in Fig. 5.

\subsection{Preparation and Application of Immunoliposomes}

Immunoliposomes are obtained by the linkage of antigen specific molecules to their surface. In Fig. 6, a schematic view of the coupling of antibodies, fragments, and smaller molecules ( $c f$. Fig. 5) to drugcarrying liposomes is given. The covalent linkage of such molecules to the surface of liposomes can be effected by various methods. A variety of bifunctional reagents are available which offer multiple coupling possibilities [45] [46]. We have investigated the coupling of antibodies to liposomes using $N$-succinimidyl- $S$-acetylthioacetate (SATA) and $N$-succinimidyl-3(2-pyridyldithio)propionate (SPDP) as bifunctional linkers.

In Fig. 7, scanning electron micrographs from in vitro incubations of liposomes $(a)$ and immunoliposomes $(b)$ with EL4 T-cell lymphoma cells are shown. Few liposomes and liposome aggregates are unspecifically adsorbed to the cell surface $(a)$, whereas the antibody mediated binding of the immunoliposomes is demonstrated in $(b)$ where a high number of single liposomes bound to the cell surface and the protruding microvilli can be recognized [47].

\section{Liposomes as Carriers for Contrast Agents}

For the improvement of diagnostic accuracy in computed tomography (CT) and in magnetic-resonance imaging (MRI), liposomal contrast agents are being investigated. In CT, multilamellar liposomes have been used as carriers for $\mathrm{I}^{125}$ labeled X-ray

\section{Fragmentation of an Antibody into Subunits}

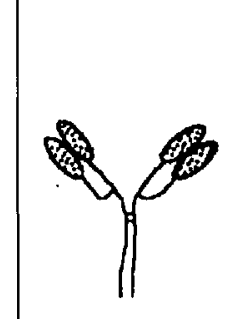

IgG Antibody: - Murine - Chimeric - Human (modified)
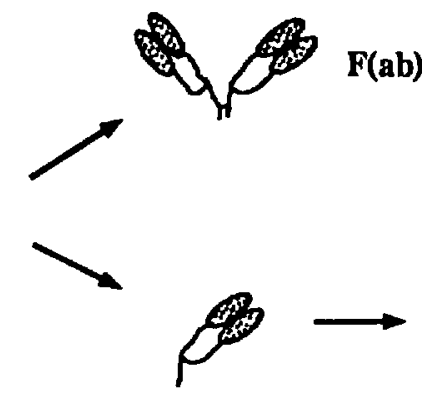

Fab Fragment

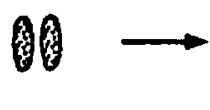

$F(a b)_{2}$ Fragment

$F_{\nabla}$

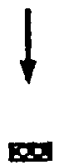

Minimal reactive Unit (mru)

Fig. 5. Antibody fragmentation into subunits. With biochemical or molecular biological methods small subunits of an antibody can be obtained (adapted from [44]). These subunits can $e . g$. be used for the preparation of immunoliposomes (cf. Fig. 6 ).

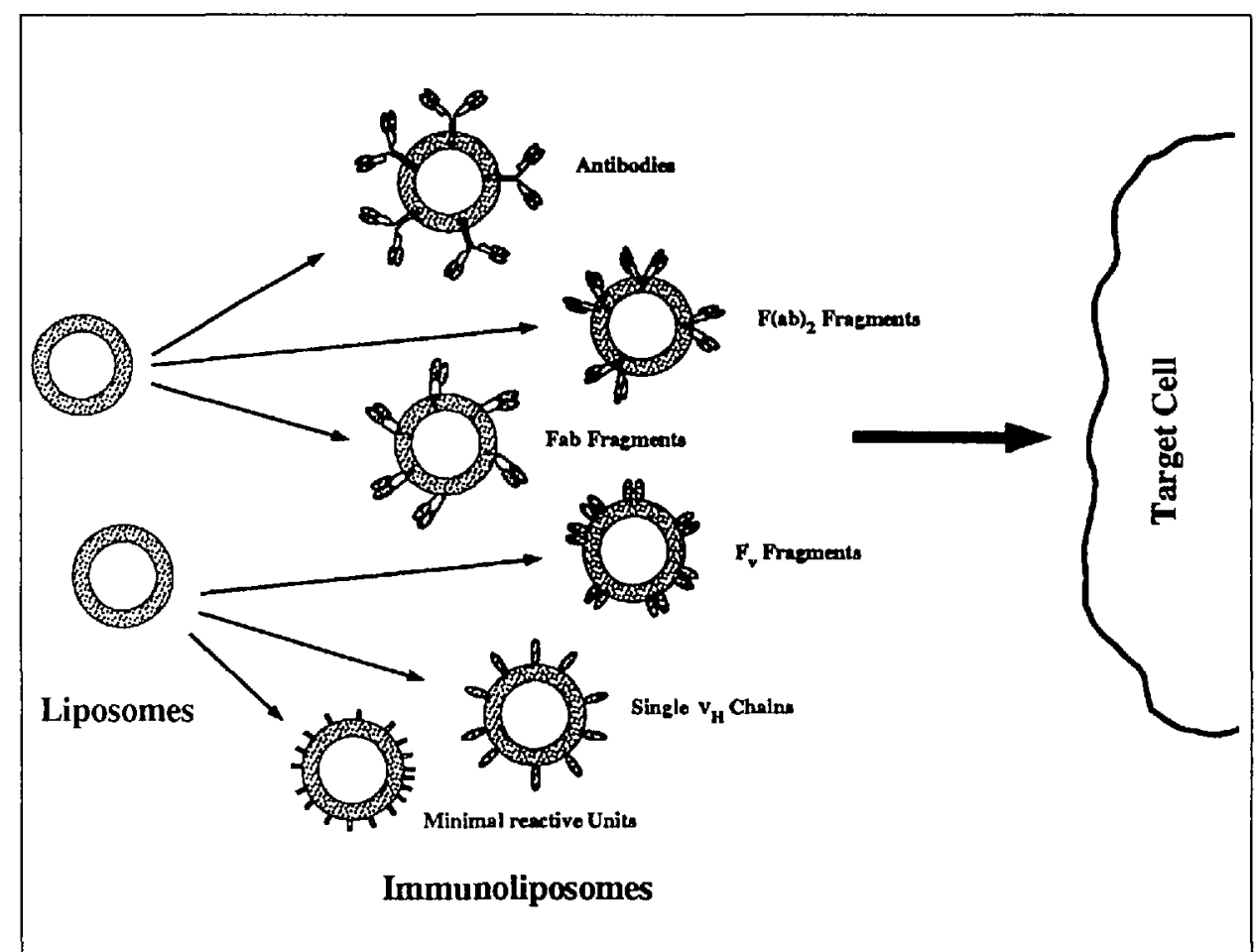

Fig. 6. Liposome - immunoliposome - target cell binding. Drug-containing liposomes are modified with target cell-specific antibodies or subunits to immunoliposomes which can bind via specific interactions to target cells (e.g. tumor cells).

contrast agents for the imaging of liver and spleen [12]. In MRI, paramagnetic complexes were encapsulated into liposomes also with the intension to improve contrast in the abdominal organs. Paramagnetic ions $\left(\mathrm{Gd}^{3+}, \mathrm{Fe}^{3+}, \mathrm{Mn}^{2+}\right)$ have the property to enhance the spin-lattice relaxation of protons which increases the contrast of the tissue where these ions are located [48]. Because of the toxicity of these ions, stable complexes with ligands like diethylen- etriaminepentaacetic acid (DTPA) have to be formed [49]. We have prepared liposomes containing a lipophilic derivative of DTPA, namely DTPA-stearate, for the complexation with $\mathrm{Gd}^{3+}, \mathrm{Fe}^{3+}$, and $\mathrm{Mn}^{2+}$ as paramagnetic ions. As shown in Fig. 8 , $\mathrm{Gd}^{3+}$-DTPA-stearate liposomes are distributed at very high concentrations in the liver. MR imaging of the liver was performed with rats and dogs, and strong contrast enhancement persisted $1-5 \mathrm{~h}$ af- 
ter application of the liposomal preparation [50][51]. As shown in Fig. 8, the initially high blood concentration of the liposomal $\mathrm{Gd}^{3+}$-chelate is decreasing, as liver accumulation is increasing. In MRI, contrast agents for the vascular system are needed, and attempts are being made to increase the blood circulation times of paramagnetic ion chelates by attachment to macromolecules and particulate carriers [52][53]. The modification of chelatecarrying liposomes with PEG derivatives as described above ( $c f .2 . l$ ) may allow the use of such preparations for the imaging of the vascular system.
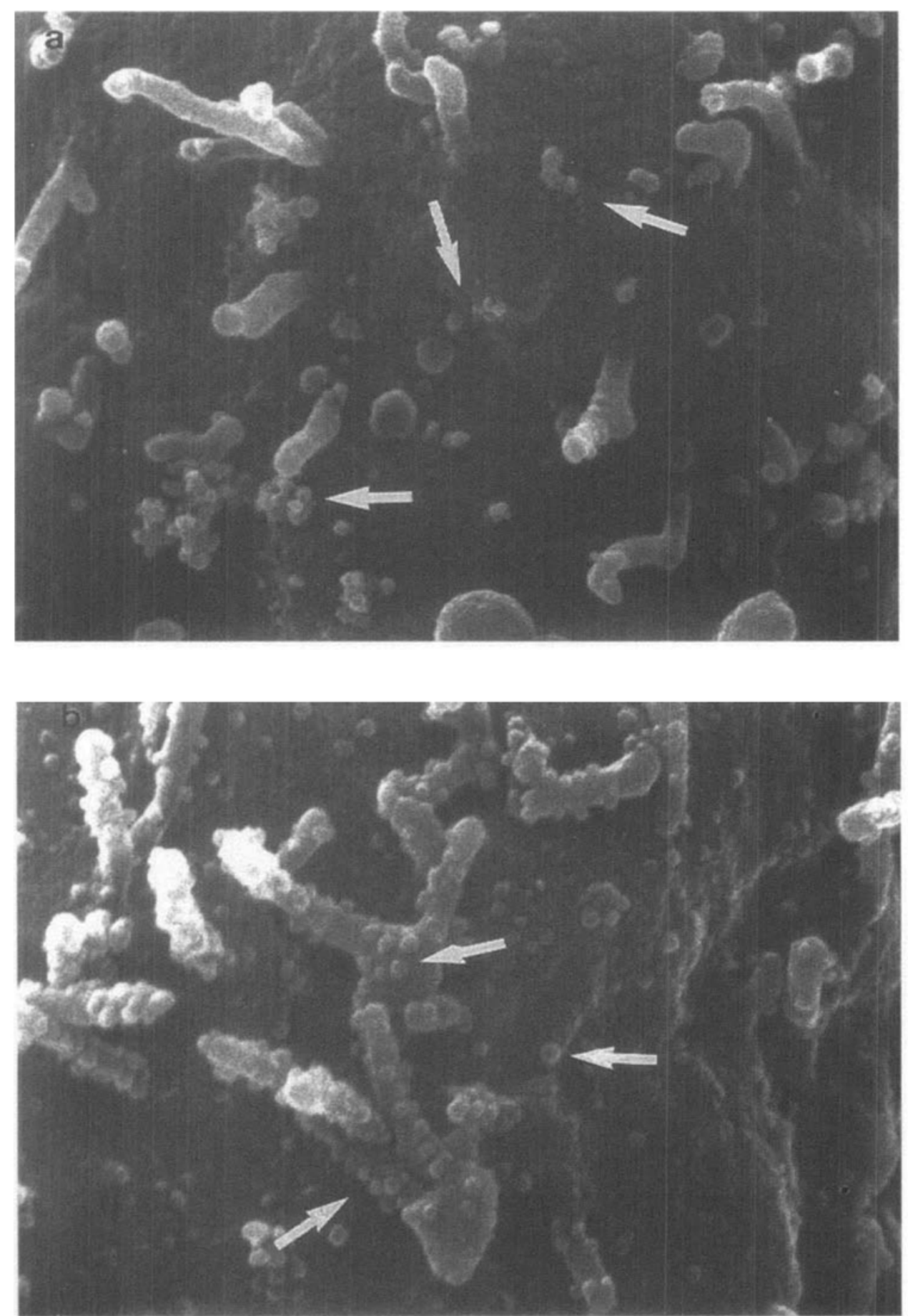

Fig. 7. Scanning-electron-microscope pictures of unspecific liposome - cell binding and specific antibody-mediated binding of immunoliposomes to the surface of an ELA lymphoma cell. Liposomes and immunoliposomes (arrows) are adsorbed $(a)$ or bound $(b)$ to the surface and to microvilli of the cell. Bar, $1 \mu \mathrm{m}$. Modified from [47].

In biological research, fluorescent liposomes are used for many purposes [1315]. Similar to drugs and contrast agents, fluorescent molecules can either be encapsulated in the trapped aqueous volume or incorporated into the lipid membrane of a liposome. The binding of liposomes and immunoliposomes to target cells can be monitored by flow cytometry and/or fluorescence microscopy. We demonstrated specific liposome binding to tumor cells

\section{Fluorescent Liposomes and Their Use in Cytofluorometry and Immuno- fluorescence}

\section{initis}

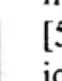
[54]. Such $\mathrm{Eu}^{3+}$-chelates have found various applications in fluoroimmunoassays [55][56]. In collaboration with the Institute of Biomedical Engineering of the ETH-Zürich (Prof. M. Anliker), we are developing a method which allows the use of time-resolved fluorescence (TR-FCM) in flow cytometry [57][58]. To achieve a signal to noise ratio which is high enough for the detection of a low number of antibodies bound to a cell ca. $500 \mathrm{Eu}^{3+}$-chelates per antibody are necessary [58]. For this purpose, we are developing liposomes which can carry high numbers $\left(>500-10^{6}\right)$ of either a $\mathrm{H}_{2} \mathrm{O}$-soluble $\mathrm{Eu}^{3+}$ complex or a lipophilic derivative of this complex. The concept of specific binding of Eu ${ }^{3+}-\mathrm{la}$ beled immunoliposomes to target cells is shown in Fig. 9. A biotinylated anti-CD8 antibody is noncovalently linked via avidin to biotinylated liposomes containing entrapped chelate complexes of $\mathrm{Eu}^{3+}$ with 4,7-bis(chlorosulfophenyl)-1,10-phenanthroline-2,9-dicarboxylic acid (Eu ${ }^{3+}-\mathrm{BCP}$ DA) and BHPD as short-lived fluorescence marker [47] [54]. These immunoliposomes contain sufficient Eu molecules to allow the detection of target molecules on autofluorescent cells [57]. For the measurement of time-resolved fluorescence, a conventional cytometer was modified enabling the time delayed detection of the $\mathrm{Eu}^{3+}$-fluorescence after the extinction of short lived autofluorescence [58]. With both methods, conventional FCM using the liposomal BHPD fluorescence and TRFCM of the liposomal $\mathrm{Eu}^{3+}$-chelates, we could demonstrate as preliminary results specific liposome binding via the CD8 antigen on human lymphocytes.

\section{Experimental}

Materials. Soy phosphatidylcholine (SPC, Epikuron 200) was from L. Meyer, Hamburg, FRG, egg phosphatidyl choline and phosphatidic acid were from Lipid Products, S. Nutfield, U.K. Cholesterol (recrystallized from $\mathrm{MeOH}$ ), choles- 
teryl-poly(ethylene glycol) 900 sebacat (cholPEG(900), stearylamine, and thioglycerol were from Fluka. Sodium cholate, DL- $\alpha$-tocopherol, org. solvents and buffer salts were from Merck, Darmstadt, FRG. The ara-C derivatives were synthesized as described in [29]. The fluorescent probe BHPD was synthesized by Demmig and Langhals [59]. Mitoxantrone dihydrochloride was from Lederle Arzneimittel $\mathrm{GmbH}$, Wolfratshausen, FRG. All other reagents used were of anal. grade and from Fluka or Merck. The radioactive salts $\mathrm{NaI}^{125}, \mathrm{Gd}^{153} \mathrm{Cl}_{3}, \mathrm{Fe}^{59} \mathrm{Cl}_{3}$, and $\mathrm{Mn}^{54} \mathrm{Cl}_{2}$ were obtained from Amersham Int., Amersham, U.K.

Methods. Liposomes containing the ara-C derivatives $N^{4}$-oleyl-ara-C and the $N^{4}$-alkyl-ara$\mathrm{C}$ compounds ( $c f$. Table 2 ) were prepared in vol. of 20-50 $\mathrm{ml}$ by detergent dialysis as described in [29]. Briefly, the org. $\left(\mathrm{CHCl}_{3} / \mathrm{MeOH}, 1: 1 \mathrm{v} / v\right)$ lipid/drug/detergent mixtures (egg- or soy phosphatidylcholine, cholesterol, lipophilic drug, charged lipid (phosphatidic acid or stearylamine), $\mathrm{DL}-\alpha$-tocopherol were dried by rotatory evaporation (Büchi rotavapor 011 ) and solubilized with 20-50 ml of phosphate buffered saline (PBS, pH 7.4). The micellar sol. were dialyzed against 10 201 PBS during $15-20 \mathrm{~h}$ in a Lipoprep $G D-1$ instrument (Diachema, Munich, FRG). After dialysis the liposomes were removed from the instrument and filtered through $0.45 \mu \mathrm{m}$ sterile filters (Van Leer Medical, Irigny, France).

Large Volume Liposome Preparation for Clinical Trials. The cancer drug mitoxantrone (Novantrone $\left.{ }^{(}\right)$forms a strong complex with negatively charged lipids [28]. The drug can be bound to liposomes containing phosphatidic acid by the formation of a 1:2 molar complex (cf. Fig. 1). Homogeneous and stable liposomes can be prepared by detergent dialysis in spite of the fact that mitoxantrone is a small $\mathrm{H}_{2} \mathrm{O}$-soluble molecule. The preparation of 31 of mitoxantrone liposomes with a drug concentration of $0.1 \mathrm{mg} /$ $\mathrm{ml}$ is given below.

$20 \mathrm{~g}$ of soy phosphatidylcholine (SPC, Epikuron 200), $2 \mathrm{~g}$ of cholesterol, $0.355 \mathrm{~g}$ of mitoxantrone dihydrochloride, $0.95 \mathrm{~g}$ of phosphatidic acid, and $0.12 \mathrm{~g}$ of DL- $\alpha$-tocopherol plus $20.6 \mathrm{~g}$ of sodium cholate as detergent are dissolved in $500 \mathrm{ml}$ of $\mathrm{CH}_{2} \mathrm{Cl}_{2} / \mathrm{MeOH}(1: 1 \mathrm{v} / \mathrm{v})$. After filtration and exhaustive removal of the org. solvents by rotatory evaporation (3-4 h, $40^{\circ}$ ), the lipid/drug/detergent mixture is dissolved in $500 \mathrm{ml}$ of sterile phosphate buffer (PB, $67 \mathrm{~mm}$, $\mathrm{pH}$ 7.4). After sterile filtration $(0.2 \mu \mathrm{m})$, the micelle soln. is pumped into the dialysis instrument (cf. Fig. 4) which is set up with two capillary dialysis cartridges (Baxter-Travenol, Type ST. 25 ). After dialysis of $20 \mathrm{I}$ of $\mathrm{PB}$, the mitoxantrone liposomes are collected and diluted to $3000 \mathrm{ml}$ with sterile PB. Thioglycerol $(0.5 \mathrm{~g})$ is added as an antioxidant and the liposomes are filled under sterile conditions and nitrogen purging into 100 $\mathrm{ml}$ ampoules. The liposomes have mean diameters of $60-80 \mathrm{~nm}$ and can be stored up to 12 months at $4-7^{\circ}$. The cap. dialysis method can be used for the preparation of liposome vols. of 0.1 101. The upscaling of the capillary dialysis method for the preparation of larger batches should be feasible.

Filter Extrusion. The liposomes containing $\mathrm{Eu}^{3+}$-chelates were prepared by extrusion of multilamellar liposomes through Nucleopore ${ }^{\circledast}$ (Sterico $A G$, Dietlikon) membranes of decreas-

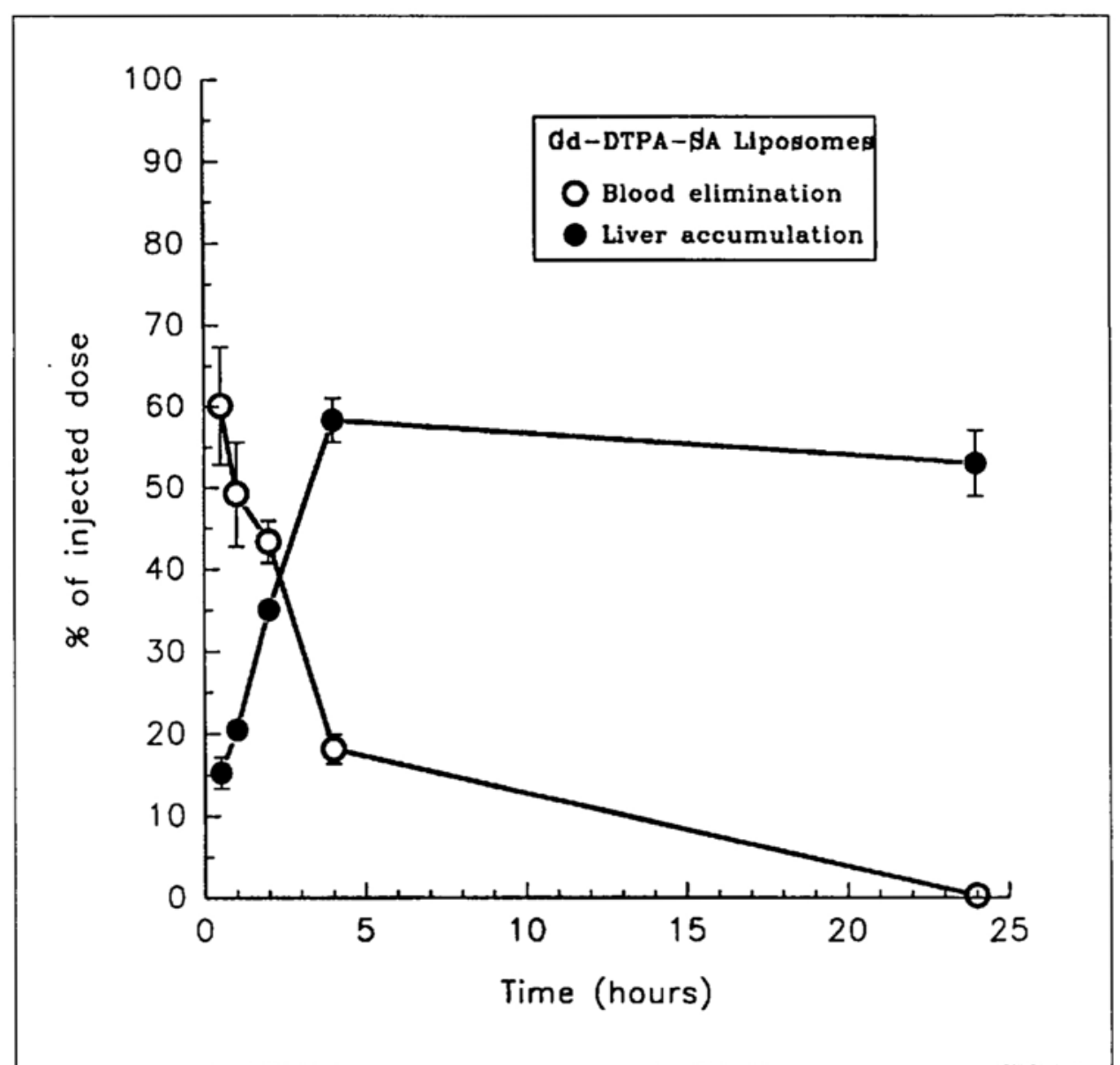

Fig. 8. Pharmacokinetics of Gd-DTPA-stearate liposomes as MRI contrast agent. The liposomes are accumulated in the liver tissue yielding high liver contrast over $\mathrm{l}-5 \mathrm{~h}$ after injection.

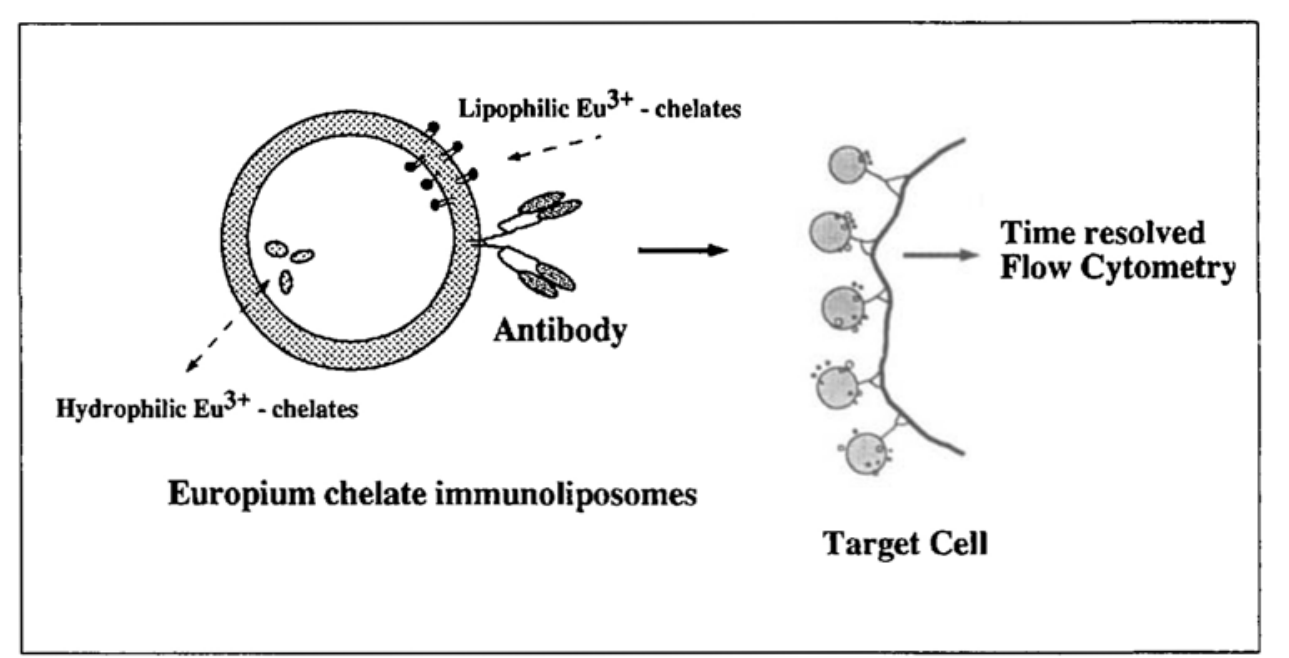

Fig. 9. Concept of the use of immunoliposomes as carriers for Eu chelates for the time-resolved detection of fluorescence on target cells

ing pore size $(0.1-0.03 \mu \mathrm{m})$ according to the method described by Hope et al. [60]. To increase the entrapment of $\mathrm{Eu}^{3+}$-BCPDA $(2-4 \mathrm{~mm})$, or generally of small hydrophilic molecules, into the liposomes, the MLV's were frozen and thawed in 3-4 cycles in liquid $\mathrm{N}_{2}$ and $\mathrm{H}_{2} \mathrm{O}$ of $40^{\circ}$ [61]. Then, they were repetitively extruded with a Lipex Extruder TM (Lipex Biomembranes Inc., Vancouver,Canada). Unencapsulated chelate was removed by dialysis against $\mathrm{PB}$ or by column chromatography on a BioGel P6-DG column (BioRad, Richmond, CA, USA) [57].

Liposome Characterization. The mean diameters and population homogeneities of all liposome preparations were routinely determined with a dynamic laser-light-scattering instrument ( $\mathrm{Ni}$ comp 200, Sta Barbara CA, USA) [62]. For these measurements, the liposomes were diluted 1:20 $(v / v)$ with filtered $(0.2 \mu \mathrm{m}) \mathrm{PB}$

In vivo Cytotoxicity in the L1210 Murine Leukemia Model. The evaluation of the cytostatic activity of liposomal drug preparations was performed according to the protocols of the National L1210 cells $\left(1 \cdot 10^{5}\right)$ from donor ascites were injected i.p. or i.v. into female BDFI mice (Tierfarm, $\mathrm{CH}-$ Füllinsdorf). Drug treatment was done 2 and $6 \mathrm{~d}$ after tumor cell implantation (cf. Table 2 and Fig. 3). Increase of lifespan was evaluated by calculation of the mean survival time in days Cancer Institute [63], with minor modifications. 
of the treated (T) animals as compared to that of the control (C) animals, expressed as $\mathrm{T} / \mathrm{C}$ in \% The animals were observed daily until death or $60 \mathrm{~d}$.

Pharmacokinetics and Organ Distribution of 1/25. or Gd $^{153}$-Labelled Liposomes. Radioactively labeled liposomes were used for the kinetic experiments with the PEG-modified liposomes (c.f. Fig. 2) and with the MRI contrast agent liposomes (cf. Fig. 8). The PEG-liposomes contained SPC, cholesterol, DL- $\alpha$-tocopherol and the corresponding PEG derivatives (10:2:0.01:04 mo parts) and were prepared in vols. of $5-10 \mathrm{ml}$ by dialysis as described above. ${ }^{125}$ labeled SPC was obtained by the photoreaction with 3-(trifluoromethyl)-3-( $m$-[ [ $\left.{ }^{125}\right]$ iodophenyl)diazirine (TID) as described by Brunner and Semenza [64]. The $\mathrm{I}^{125}-\mathrm{SPC}$ was added in trace amounts to the lipid mixtures and liposomes $(5-10 \mathrm{ml})$ were prepare by sodium-cholate dialysis (see above).

The liposomes containing the paramagnetic chelates $\mathrm{Gd}^{3+}$-, $\mathrm{Fe}^{3+}$, and $\mathrm{Mn}^{2+}$-DTPA-stearate were composed of SPC, cholesterol, DL- $\alpha$-tocopherol, DTPA-stearate (10:2:0.01:2-6 mol parts) The liposomes were prepared by cap. dialysis using a small dialyzer cartridge (Baxter-Traven$o l, S T-12)$ allowing the preparation of batches of $50-200 \mathrm{ml}$. Traces of $\mathrm{Gd}^{153} \mathrm{Cl}_{3}, \mathrm{Fe}^{59} \mathrm{Cl}_{3}$, and $\mathrm{Mn}^{54} \mathrm{Cl}_{2}$ were added during complex formation to the DTPA-stearate liposomes as desribed be fore $[50 \| 51]$

The pharmacokinetic parameters and organ distribution data were obtained as follows: male or female rats (ZUR:SIV, Institut für Zuchthygiene, University of Zürich) of 160-240 g b. wt were used. Liposomes $(0.5-1.5 \mathrm{ml})$ containing 30 $\mu \mathrm{M}$ of the metal chelate were injected $i . v$. into the tail vein or the exposed jugular vein. Three animals per time point were used and killed after 0.5 $1,2,4,24,72$, and $192 \mathrm{~h}$. Blood and the main organs were removed and the concentration of the radioactively labeled chelates determined in a gamma counter (Packard Auto-gamma 5000) Pharmacokinetic parameters were calculated as described in [50][5I]. The distribution of $\mathrm{Gd}^{3+}$ DTPASA in liposomes in blood and liver are shown in Fig. 8

Immunoliposomes. Antibody Modification and Liposome Coupling. The detailed methods of antibody modification and coupling to liposomes are given in [47]. Summarized, the IgG monoclonal antibodies (anti-B8-24.3, anti-IB 16-6) were modified with the bifunctional coupling reagents SPDP (Pharmacia) and SATA. SATA was synthesized according to Duncan et al. [65] Optimal coupling conditions ( molar ratios of SATA: antibody, incubation time, temperature $\mathrm{pH}$ ) were determined. The modified antibodie were linked to liposomes of the usual-composi tion (SPC, cholesterol, DL- $\alpha$-tocopherol). Additionally, the liposomes contained NOAC as cytostatic drug and a lipophilic maleimide derivative ( $N$-(3-maleimidopropionyl)- $N^{2}$-palmitoyl-1. lysine methyl ester, (MP-PL)) to which the SATA modified antibodies could be attached via a thioether linkage. To be able to determine liposome - cell binding by flow cytometry the lipophilic fluorescent marker BHPD was incorporated into the liposome membranes.

Binding experiments of liposomes and targe cell specific immunoliposomes were made as follows: target cells $\left(1.5 \cdot 10^{6} \mathrm{EL} 4\right.$ or B 16 melanoma cells) suspended in PB were mixed with liposomes ( $1-130 \mathrm{~nm}$, corresponding to $0.02-$
$2.5 \cdot 10^{6}$ liposomes/cell) in a vol. of $0.4 \mathrm{ml}$. After incubation during $60 \mathrm{~min}$ at $4^{\circ}$ and several washing cycles, the cell-bound liposomal BHPD fluorescence intensity was measured on an Epics Profile Fluoro Cvtometer (Coulter Corp.) at 470 $\mathrm{nm}$ excitation and 530-nm emission wavelength.

For the scanning electron microscopy experiments ( $c f$. Fig. $7 a, b$ ) the binding of the liposomes to EL4 cells was performed as described above. After incubation, the cells were fixed with $2 \%$ glutaraldehyde and seeded on glass cover slips precoated with poly-L-lysine (Sigma, $\mathrm{M}_{\mathrm{r}}$ 60000 ). The dehydrated and dried samples were coated with gold $(10 \mathrm{~nm})$ and examined in a SEM 505 (Philips)

\section{Concluding Remarks}

In this review of the author's recent work, it is demonstrated that liposomes can be used as very versatile macromolecular carriers for a large diversity of hydrophilic or lipophilic molecules. The use of liposomes as drug carriers for in vivo applications offers several advantages over other carrier systems. Liposomes can be prepared with natural, untoxic, and degradable lipids, and the liposome membrane can be composed according to particular requirements. Size and homogeneity which contribute to the in vivo properties of liposomes can also be influenced by the use of appropriate preparation methods and by selection of the lipid composition. Compared to other carrier systems like albumins, dextrans, antibodies, nanocapsules, etc., liposomes offer the advantage that significantly higher numbers of small molecules can be loaded into one vesicle. Generally, an antibody can carry 10-50 small molecules without impairment of its specific binding activity. The loading capacity of albumins and dextrans varies between 100 to a few thousands of molecules, whereas liposomes can be loaded with very high numbers of small molecules. For example, a 1 mm solution of ara$\mathrm{C}$ entrapped in $1 \mathrm{ml}$ of liposome suspension with an entrapment efficiency of $1 \%$ yields $6 \cdot 10^{15}$ trapped ara-C molecules per liposome. The entrapment of high numbers of small hydrophilic molecules into the inner aqueous space of a liposome has the disadvantage that these molecules leak through the lipid bilayer and that, therefore, stable preparations are not obtained

Lipophilic molecules like, e.g. the ara$\mathrm{C}$ derivatives $N^{4}$-oleyl-ara-C and $N^{4}$-hexadecyl-ara-C can be incoporated at numbers of $10^{4}-10^{5}$ molecules per liposome depending on the drug properties, and on size and concentration of the liposomes Here, the incorporation efficiency is virtually quantitative and liposome preparations of high stability are obtained

With the possibility to vary these parameters, optimized liposomal prepara- tions can be obtained which meet the requirements of their intended application. Liposomes loaded with an antitumor drug can either be made to stay in circulation, when a circulating leukemia cell is the target, or the liposomes are composed and prepared in such a fashion that they accumulate in the liver, when a liver tumor or tumor metastases have to be treated. The natural distribution and elimination kinetics of liposomes can further be altered by the attachment of cell-specific antibodies or antibody subunits to the liposome surface. With the concept of cell-specific immunoliposome binding, higher uptake of cytostatic drug molecules in the tumor cell and less unwanted toxic effects on healthy cells are expected. The circumvention of multidrug resistance of tumor cells by their treatment with liposomal cytostatic drugs may be possible. Uptake mechanisms and intracellular drug distribution of drugs delivered by liposomes to resistant cells are presently under investigation [10]

The clinical utility of liposomal drug preparations depends on the availability of large batch preparation methods. Most of the presently used methods allow only the preparation of small batch volumes for laboratory use. Methods which allow the preparation of larger liposome batches are under development. The filter extrusion and detergent-dialysis methods can readily be enlarged in scale. The detergentdialysis instrument described in this publication allows the preparation of intermediate batches of $0.1-101$ of liposomes. It can easily be set up and operated in a sterile facility, e.g. in a hospital pharmacy. The utilization of this method could allow the performance of important clinical trials with liposomal drug preparations.

The lyophilization of liposomes would greatly encourage the use of clinical liposome applications. The method is under investigation, and lyophilized MLV's containing muramyltripeptides are in use [21]. The future developments in this field may contribute to new approaches of the use of known drugs, of insoluble lipophilic molecules as intravenous application forms, of more effective and less toxic preparations, of new vaccination methods and of general aspects of drug-membrane Interactions.

The author wishes to thank $H$. Hengartner, H. Schott, Ch. Sauter, B. Pestalozi, P. Groscurth, G.K. von Schulthess, P. Weber, and $M$. Condrau for their valuable support. This work was partially supported by the Krebsliga of the Kanton Zürich, the Radium Stiftung, the Swiss National Science Foundation grants No. 3.8160.86 and 32-29979.90), Lederle Arzneimittel GmbH, Wolfratshausen, FRG, and the Deutsche Krebshilfe. 
Received: October 25, 1991

[I] G. Gregoriadis, Ed., in 'Liposome Technology', CRC Press, Boca Raton, 1984, Vols. $1-4$.

[2] G. Poste, R. Kirsh, P. Bugelski, in 'Novel Approaches to Cancer Chemotherapy', Ed P.Sunkara, Academic Press, London, 1984

[3] M.C. Woodle, D. Papahadjopoulos, Meth Enzymol. 1989, I7I, 195.

[4] M. Ostro, P. Cullis, Am J. Hospital Pharm. 1989, 46, 1576

[5] J.H. Senior, CRC Crit. Rev. Ther. Drug Carrier Syst. 1987, 3, 123.

[6] A.L. Klibanov, K. Maruyama, V.P. Torchilin, L. Huang, FEBS Lett. 1990, 268, 235.

17] J.H. Senior, C. Delgado, D. Fisher, C. Tilcock, G. Gregoriadis, Biochim. Biophys. Acta 1991, 1062, 77.

[8] G. Blume, G. Cevc, Biochim. Biophys. Acta 1990, $1029,91$.

(9) R.E. Pagano, J.N. Weinstein, Ann. Rev. Biophys. Bioeng. 1978, 7, 435.

[10] S. Oudard, A. Thierry, T.J. Jorgensen, A Rahman, Cancer Chemother. Pharmacol. 1991, 28, 259

[1I] D.E. Brenner, J. Natl. Cancer Inst. 1989 $81,1436$.

[12] M.R. Zalutsky, M.A. Noska, S.E. Seltzer, Invest. Radiol. 1987, 22, 141 .

[13] A. Truneh, P. Machy, P.K. Horan, J. Immunol. Methods 1987,100, 59.

[14] A.G. Gray, J. Morgan, D.C. Linch, E.R. Huehns, J. Immunol. Methods 1989, 121, 1.

[15] J. Connor, L. Huang, J. Cell. Biol. 1985 $101,582$.

[16] H.J. Keizer, H.M. Pinedo, Cancer Drug Deliv. 1985, 2, 147.

[17] G. Delgado, R.K. Potkul, J.A. Treat, G.S Lewandowski, J.F. Barter, D. Forst, A Rahman, Am. J. Obstet. Gynecol. 1989, 160,812 .

[18] A. Gabizon, A. Sulkes, T. Peretz, S. Druckmann, D. Goren, S. Amselem, Y. Barenholz, in 'Liposomes in the Therapy of Infectious Diseases and Cancer', Eds. G. Lopez-Berenstein and I.J. Fidler, A. Liss, New York, 1989, 391.

[19] J.P. Sculier, A. Coune, C. Brassine, C. Laduron, G. Atassi, J.M. Ruysschaert, J. Frühling, J. Clin. Oncol. 1986, 4, 789

[20] G. Lopez-Berenstein, in 'Liposomes in the Therapy of Infectious Diseases and Cancer', Eds. G.Lopez-Berenstein and I.J. Fidler, A. Liss, New York, 1989, p. 317.

121] J.L. Murray, E.S. Kleinerman, J.R. Tatom, J.E. Cunningham, J. Lepe-Zuniga, J.U. Gutterman, K. Andrejcio, I.J. Fidler, I.H Krakoff, in' Liposomes in the Therapy of Infectious Diseases and Cancer', Eds. G. Lopez-Berenstein and I.J. Fidler, Liss, New York, 1989, p. 329

[22] C.A. Presant, R.T. Proffitt, A. Franklin Turner, L.E. Williams, D. Winsor, J.L. Werner, P. Kennedy, C. Wiseman, K. Gala, R.J. McKenna, J.D. Smith, S.A. Bouzaglou, R.A. Callahan, J. Baldeschwieler, R.J. Crossley, Cancer 1988, 62, 905

[23] S.D. Harrison, P.J. O'Dwyer, M.W. Trader, Cancer Res. 1986, 46, 3396.

[24] T.H. Corbett, B.J. Roberts, M.W. Trader W.R. Laster, D.P. Griswold, F.M. Schabel, Cancer Treat. Rep. 1982, 66, 1187.
[25] V. Heinemann, D. Murray, R. Walters, R.E. Meyn, W. Plunkett, Cancer Chemother. Pharmacol. 1988, 22, 205.

[26] S. Amadori, G. Meloni, M.C. Petti, G. Papa, R. Minero, F. Mandelli, Leukemia $1989,3,112$

[27] H.M. Kantarjian, R.S. Walters, M.J. Keating, M. Talpaz, B. Anderson, M. Beran, K.B. McCredie, E.J. Freireich, Cancer 1988, 62, 672

[28] R.A.Schwendener, H.H. Fiebig, M.R. Berger, D.P. Berger, Cancer Chemother. Pharmacol 1991, 27, 429.

[29] W. Rubas, A. Supersaxo, H.G. Weder, H.R Hartmann, H. Hengartner, H. Schott, R.A Schwendener, Int. J. Cancer 1986, 37, 149.

[30] R.A. Schwendener, H. Schott, H.R. Hartmann, A. Supersaxo, W. Rubas, H. Hengartner, Onkologie 1987, 10, 232.

[31] M. Aoshima, S. Tsukagoshi, Y. Sakurai, J Oh-Ishi, T. Ishida, H. Kobayashi, Cancer Res. 1976, 36, 2726.

[32] R.A. Schwendener, B. Pestalozzi, S. Berger, H. Schott, H. Hengartner, Ch. Sauter, in 'Liposomes in the Therapy of Infectious Diseases and Cancer, Eds. G.Lopez-Berenstein and I.J. Fidler, A. Liss, New York, 1989, p. 95.

[33] B. Pestalozzi, R.A. Schwendener, Ch.Sauter, Annals Oncol. 1992, in press.

[34] R.A. Schwendener, Cancer Drug Deliv. 1986, 3,123

[35] R.A. Schwendener, in 'Liposome Technology', 2nd edn., Ed. G. Gregoriadis, CRC Press, Boca Raton, Florida, 1992, Vol. 1, in press.

[36] R.O. Dillman, Ann. Inter. Med. 1989, III, 529.

[37] A.A. Hertler, A.E. Frankel, J. Clin. Oncol. $1989,7,1932$.

[38] L.G. Durrant, V.S. Byes, PJ. Scannon, R Rodvien, K. Grant, R.A. Robins, R.A. Marksman, R.W. Baldwin Clin. Exp. Im munol. 1989, 75, 258

[39] M.A. Till, V. Ghetie, T. Gregory, E.J. Patzer, J.P. Porter, J.W. Uhr, D.J. Capon, E.S Vitetta, Science 1988, 242, 1166.

[40] KC. Ballantyne, A.C. Perkins, M.V. Pimm M.C. Garnett, J.A. Clegg, N.C. Armitage, R.W. Baldwin, J.D. Hardcastle, Int. J. Cancer 1988, Suppl. 2, 103.

[41] E. Diener, U.E. Diener, A.Sinha, S. Xia, R. Vergidis, Science 1985, 23I, 148.

[42] C.H.Ford, C.E. Newman, J.R. Johnson, Br. J. Cancer 1983, 47, 193.

[43] J.P.Case, H. Lorberboum-Galski, R. Lafyatis, D. FitzGerald, R.L. Wilder, I. Pastan, Proc. Natl. Acad. Sci. U.S.A, 1989, 86, 287.

[44] G. Winter, C. Milstein, Nature (London) 1991, 349, 293.

[45] V.P. Torchilin, A.L. Klibanov, CRC Crit. Rev. Ther. Drug Carrier Syst. 1991, 7, 275

[46] M. Wilchek, E.A. Bayer, Anal. Biochem. 1988, $17 I, 1$

[47] R.A. Schwendener, T. Trüb, H. Schott, H Langhals, R.F. Barth, P. Groscurth, H Hengartner, Biochim. Biophys. Acta 1990 $1026,69$.

[48] J.A. Pople, W.G. Schneider, H.J. Bernstein, Eds. in 'Highresolution Nuclear Magnetic Resonance', McGraw-Hill, New York, 1959.

[49] H.J. Weinmann, R.C. Brasch, W.R. Press, G.E. Wesbey, Am. J. Radiol. 1984, 142 619
[50] R.A. Schwendener, R. Wüthrich, S. Duewell, G. Westera, G.H. von Schulthess, Int. J. Pharm. 1989, 49, 249

[51] R.A. Schwendener, R. Wüthrich, S. Duewell, E. Wehrli, G.K. von Schulthess. Invest Radiol 1990, 25, 922

[52] S. Wang, M.G. Wikström, D.L. White, J. Klaveness, E. Holtz, P. Rongved, M.E. Moseley, R.C. Brasch, Radiology 1990 , 175,483 .

[53] M.D. Ogan, U. Schmiedl, M.E. Moseley, W. Grodd, H. Paajanen, R.C. Brasch, $/ h-$ vest. Radiol. 1987, 22, 665

[54] R.A. Evangelista. A. Pollak, B. Allore, E.F. Templeton, R.C. Morton, E.P. Diamandis, Clin. Biochem. 1988, 21, 173.

[55] E.P. Diamandis, R.C. Morton, J. Immunol. Methods 1988, $1 / 2,43$.

[56] H.P. Knopf, R. Papoian, J. Immunol. Methods 1991, 138, 233.

[57] R.A. Schwendener, P. Weber, M.A. Condrau, Cytometry 1991, Suppl. 5, 102

[58] M.A.Condrau, R.A.Schwendener, M.Zimmermann, P. Rol, W. Fierz, P. Niederer, $M$. Anliker, Cytometry 1991, Suppl. 5, 101.

[59] S.Demming, H. Langhals, Chem. Ber. 1988. $I 2 I, 225$.

[60] M.J. Hope, M.B. Bally, G. Webb, P.R. Cullis, Biochim. Biophys. Acta 1985, $\$ / 2$, 55

[61] L.D. Mayer, M.J. Hope, P.R. Cullis, A.S. Janoff, Biochim. Biophys, Acta 1985, 817 , 193.

[62] M.H.W. Milsmann, R.A. Schwendener, H.G. Weder, Biochim. Biophys. Acra 1978 , $5 / 2,147$

[63] R.I. Geran, N.H. Greenbert, M.M. MacDonald, A.M. Schumacher, B.J. Abbott, Cancer Chemother Rep. Part III 1972, 3, 47.

[64] J.Bunner, G.Semenza, Birchemistry 1981, 20,7174.

[65] R.J.S. Duncan, P.D. Waston, R. Wriggleseworth, Anal. Biochem. 1983, 132,68. 